\title{
Improvement of Deadbeat Control for PV Converter
}

\author{
Liyue Zhang, Fanzheng Zeng*, Weiliang Zhang, Yun Su, Chunjie Zhou, Shunde Pan and Chenge Ye \\ HeZhou University, HeZhou, Guangxi 542899, China \\ ${ }^{*}$ Corresponding author
}

\begin{abstract}
In this paper, the deadbeat control of singlephase photovoltaic(PV) grid connected converter is studied, and the mathematical model of the control model is derived. The application of a large number of power electronic equipment will be reduced, considering the direct power supply of the DC load by the distributed power supply. In this paper, distributed generation is used as photovoltaic power generation system. It adopts maximum power point tracking control(MPPT), and sends part of power directly to DC load. The surplus power is transported to the grid, which not only ensures the maximum efficiency of energy, but also reduces the cost. In addition, this paper gives the real time calculation formula of inductance, and realizes the more precise control of the system by calculating the inductance on line. Finally, the system has been simulated and verified with Simulink.
\end{abstract}

\section{Keywords-converter; DC load; MPPT}

\section{INTRODUCTION}

At present, the traditional fossil energy is decreasing, and the demand for electricity is increasing. In order to solve the contradiction between supply and demand and alleviate the energy crisis, renewable energy has been paid more and more attention. Renewable energy, through distributed generation technology, converts wind, solar, water, and ocean energy into electrical energy that is urgently needed[1]. Among them, photovoltaic power generation is one of the most concerned distributed new energy generation power generation. It can run on the island mode, and at the same time, it can be connected by the inverter to the distribution network[2]. The converter can enable the two-way flow of power to achieve the mutual supply of energy between the AC side and the DC side. Meanwhile, under the grid connected mode, the DC bus voltage is maintained by the distribution network, and the photovoltaic system works at the maximum power point tracking, which improves the stability and energy utilization ratio of the system[3].The PV system diagram in this paper is shown in Figure I.

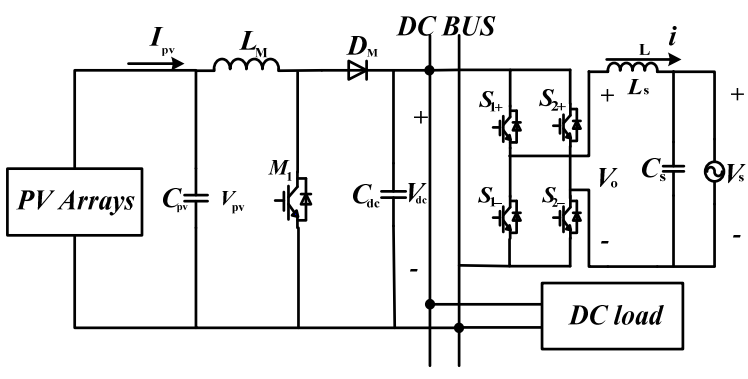

FIGURE I. PV SYSTEM DIAGRAM

In the traditional deadbeat control, the method of pulse width modulation (PWM) is used to control the converter. A predictive deadbeat power control is proposed in document [4]. This method greatly reduces the content of harmonic power, improves the steady-state performance and keeps the dynamic performance unchanged. In document [5], a deadbeat control scheme based on current prediction correction is proposed, which effectively reduces the adverse effects of random sampling error. At the same time, the robust performance of the system is improved. In document [6], a new deadbeat control is proposed, which can maintain good dynamic performance when the start or load changes. Document [7] proposed an improved deadbeat direct power control, which made the system's dynamic and steady-state performance very good, and realized the decoupling control of active power and reactive power. However, these literatures do not consider the influence of the parameters of the original energy storage on the system and the situation when the DC load is connected to the PV system.

In this paper, the variation of the inductance value with the change of current and the change of capacitance value with voltage are considered, and the corresponding mathematical deduction is given, and the corresponding mathematical expression is given. At the same time, the DC load is taken into account, and the control block diagram is given. The mathematical model of the photovoltaic system and the discrete state space model are derived. Finally, the whole system is simulated and verified.

\section{State Model of DeadBeat Control System}

\section{A. Basic Principle}

Deadbeat control is a discrete digital control method. It has good dynamic performance and very fast transient response, Therefore, it is very suitable for the intermittent distributed generation system which is easily affected by the environment, and especially suitable for the control of the photovoltaic grid 
connected inverter [8].The premise of deadbeat control is the derivation of system state equation, and then combines with the output signal of feedback, attains the control purpose By deriving the conduction time of the next cycle inverter.

\section{B. State Model Derivation}

As shown in Figure I, according to Kirchhoff's law, the differential equation of the Photovoltaic system can be expressed as:

$$
L \frac{d i_{L}}{d t}+V_{s}=V_{o}
$$

Vo is the output voltage of the inverter and the Vs is the power supply voltage. After the (1) type discretization can be obtained:

$$
L \frac{i_{k+1}-i_{k}}{T_{s}}+V_{s}=V_{o}
$$

As a result, the deadbeat control can be achieved easily through the system parameters. The formula (2) shows that the deadbeat control is influenced by the value of the inductance.

In document [9], the linear relationship between the inductance current and the DC bus voltage is established, and the relation is as follows:

$$
V_{d c}=V_{d c 0}+k I_{L}
$$

In the formula, $V_{d c}$ is DC bus voltage. $V_{d c o}$ is the rated voltage of the DC bus, and the $K$ is the slope which value is the ratio of the allowable voltage variation to the current change. $I_{L}$ is the inductance current value. In this paper, the instruction value of the inductor current varies with the change of the bus voltage. That is, the load affects its instruction value. The expression of the instruction value is as follows:

$$
\Delta I_{A}(n)=\frac{C_{\mathrm{dc}}}{T_{1}}\left[\Delta V_{d c}(n)-\Delta V_{d c}(n+1)\right]
$$

In the formula, the $T_{l}$ is a linear period, and the $C_{d c}$ is a DC bus capacitor. The formula (4) shows that the inductance current is influenced by the capacitance value of the DC bus.

\section{Determination Of The Value Of Inductance And Capacitance}

According to the document [9], the calculation formula of the capacitance value is as follows:

$$
C_{d c}^{\prime}=C_{d c, n} \cdot \frac{\Delta V_{d c, d}(n+1)}{\Delta V_{d c}(n+1)}
$$

$C_{\mathrm{dc}, \mathrm{n}}$ is the capacitance value of at time $n$, and the $\Delta V_{\mathrm{dc}}(n+1)$ is the voltage change of the bus voltage at time $n+1$.

$$
\Delta V_{d c, d}(n+1)=V_{d c}(n)-V_{d c, d}(n+1)
$$

$V_{\mathrm{dc}, \mathrm{d}}(n+1)$ is expected to output DC bus voltage at time $\mathrm{n}+1$.

In document [10], a formula for calculating the value of a piecewise linear inductance is given.

$$
L_{s}(N)=\frac{T\left[U_{d c}(N)-U_{s}(N)\right]}{i_{s}(N+1)-i_{s}(N)}
$$

$L s(N)$ is the real time estimation of the inductance, $T$ is the sampling period, and the $N$ is the sampling point. Through the expression of the inductance value and the capacitance value given by (5) and (7), the real time inductance and capacitance value can be solved.

\section{Calculation Of Duty Ratio Of Grid Connected Inverter}

In fact, the equivalent resistance of the circuit and converter is far less than the filter inductance, so the effect of the equivalent resistance on the circuit can be ignored. In combination with the (2) and (7) formula derived from the previous article, it can be obtained:

$$
i_{L}(k+1)=i_{L}(k)+\frac{T_{s}}{L_{s}(k)}\left[u_{o}(k)-u_{s}(k)\right]
$$

In the formula, Ts is the working cycle of the inverter, and Ls (k) is k time estimate inductance value. Us (k) is k time grid voltage, uo $(\mathrm{k})$ is $\mathrm{k}$ time inverter output voltage, iL ( $\mathrm{k}$ ) is zero time inductance current, and it is the predicted value of current time. IL $(\mathrm{k}+1)$ is the predictive value of the inductor current at the time of $\mathrm{k}+1$. The converter uses the $\mathrm{iL}(\mathrm{k}+1)$ as the reference value to realize the beat free control. There are many kinds of calculation methods for reference current, and the reference current is solved as follows. The difference between the power of the power and the power of the DC load is equal to the power that is sent to the grid. That is

$$
P_{\text {grid }}=P_{p v}-P_{\text {load }}
$$

So the reference current generated by the power is

$$
I_{\text {ref_g }}=\frac{P_{\text {grid }}}{V_{s}}=\frac{P_{p v}-P_{\text {load }}}{V_{s}}
$$

In addition, the outer loop is controlled by voltage, and the reference current produced by it is Iref_u. Therefore

$$
I_{(k+1)}=I_{r e f}=I_{r e f_{-} g}+I_{r e f_{-} u}
$$

As a result, the output voltage uo $(\mathrm{k})$ of the inverter at $\mathrm{k}$ time, such as type (12), can be obtained according to the above hypothesis recombining type (8).

$$
u_{o}(k)=\frac{L_{s}(k)}{T_{s}}\left[i_{L}(k+1)-i_{L}(k)\right]+u_{s}(k)
$$

In this paper, the inverter operates in a state connected to the 
distribution network, and the fundamental voltage of the inverter output should conform to the requirements of the grid. In this paper, the power grid voltage is:

$$
u_{s}=\sqrt{2} U_{s} \sin (\omega t)
$$

According to the formula of the average value, it can be obtained that the average value of the grid voltage at $k$ time of the sampling period

$$
\begin{gathered}
u_{s}(k)=\frac{\sqrt{2} U_{s}}{T_{s} \omega}\left[\cos (k+1) \omega T_{s}-\cos (k) \omega T\right] \\
D(k+1)=\frac{u_{o}(k)}{U_{d c}}
\end{gathered}
$$

In combination with (12), (14), (15), the duty ratio can be obtained, such as formula (16).

$$
D(k+1)=\frac{1}{U_{d c}} \cdot \frac{L_{s}(k)}{T_{s}}\left[i_{L}(k+1)-i_{L}(k)\right]+u_{s}(k)
$$

Through the duty ratio of the $\mathrm{k}+1$ time converter, the control of the inverter can be realized by the (16).

\section{SIMULATION RESULT}

\section{A. System Control Block Diagram}

Figure II is a control block diagram of photovoltaic grid connected system. Photovoltaic power generation adopts maximum power point tracking (MPPT) control. This control ensures that PV can output maximum power in various environments. When the power of the photovoltaic system is more than the load required, the grid converter will send the excess energy into the distribution network, which improves the utilization efficiency of the photovoltaic power generation. In this paper, only the on-line calculation of the inductance value is added to the control, and the magnitude of the piecewise linear inductance can be obtained by calculation.

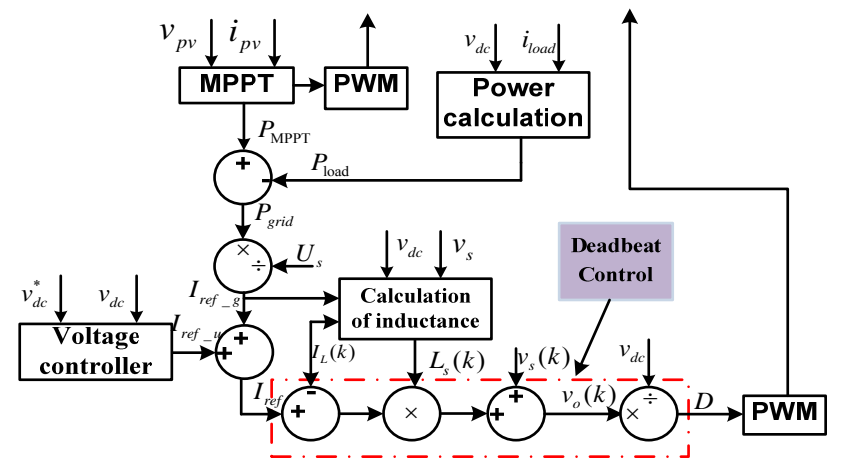

FIGURE II. CONTROL BLOCK DIAGRAM OF PHOTOVOLTAIC POWER SYSTEM

\section{B. System Parameter}

The specific parameters of the original components of the photovoltaic power generation system studied in this paper are given in Table I.

TABLE I. PARAMETER TABLE OF PHOTOVOLTAIC POWER SYSTEM

\begin{tabular}{ll}
\multicolumn{1}{c}{ parameter } & \multicolumn{1}{c}{ parameter values } \\
\hline AC voltage & $220 \mathrm{Vrms} / 50 \mathrm{~Hz}$ \\
switch frequency & $20 \mathrm{kHz}$ \\
Maximum & output \\
power & $5 \mathrm{~kW}$ \\
\hline $\mathrm{L}$ & $0.003 \mathrm{H}$ \\
$\mathrm{C}_{\mathrm{pv}}$ & $560 \mu \mathrm{F}$ \\
$\mathrm{C}_{\mathrm{dc}}$ & $5600 \mu \mathrm{F}$ \\
$\mathrm{C}_{\mathrm{ac}}$ & $4.7 \mu \mathrm{F} / 0.001 \Omega$ \\
$\mathrm{R}_{\text {load }}$ & $80 \Omega$ \\
\hline
\end{tabular}

\section{Simulation Results}

Based on the modeling and analysis of the whole photovoltaic grid system, the Matlab/simulink toolbox is used to simulate the photovoltaic system in this paper.

Figure III is the output voltage of the inverter and the waveform of the filtered inductor current. It can be seen from the diagram that the phase of the voltage and current is the same, and the unit power factor can be supplied to the power grid. Figure 3 is a DC bus voltage waveform diagram. It can be seen from the diagram that the DC bus voltage has reached a stable state when the voltage of the DC bus is in 0 . 1seconds.

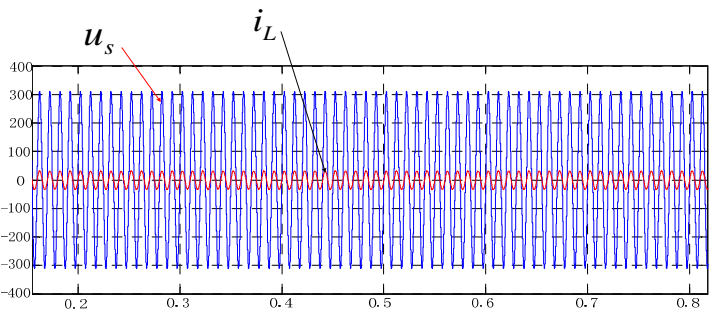

FIGURE III. WAVEFORM OF CONVERTER OUTPUT

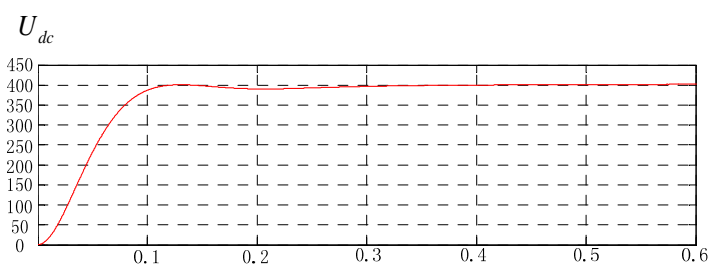

FIGURE IV. WAVEFORM OF DC BUS VOLTAGE

Figure $\mathrm{V}$ is a photovoltaic output power waveform, and its maximum power is $4.8 \mathrm{~kW}$. 


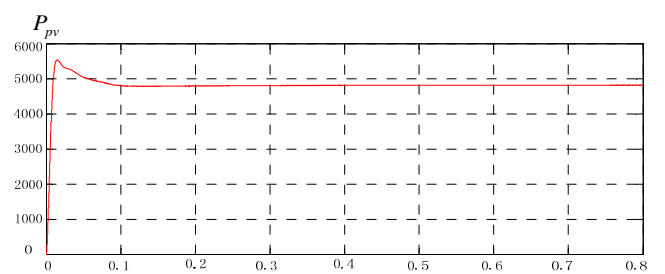

FIGURE V. OUTPUT POWER WAVEFORM OF THE PV MODULE

\section{CONCLUSION}

In this paper, the deadbeat control of photovoltaic grid connected inverter is studied, and the dynamic performance of the system and the fast transient response are improved. The photovoltaic system is controlled by MPPT, which improves the efficiency of energy utilization. At the same time, the DC load is directly supplied by the DC source, which reduces the application of the power and electronic devices. In addition, the influence of the inductance changes on the control precision of the system is considered, and the expression of the real time calculation of the inductor is given. Finally, the simulation validates the correctness of the problem.

\section{REFERENCES}

[1] LI Xialin; GUO Li; WANG Chengshan; LI Yunwei. Key Technologies of DC Microgrids: An Overview[J]. Proceedings of the CSEE, 2016 , 36(1):2-17.

[2] Jing Nan; Deng Xuanxuan; Cui Guangzhao; Dou Zhifeng. A Model Predictive Direct Power Control Method for Photovoltaic GridConnected Inverter[J]. Journal of Electrical Engineering, 2016, 11(6):1318.

[3] Cai Jihe; Li Bei; Zhang Yongchun. Research on Photovoltaic Reactive Power Control Based on SVPWM[J]. Transactions of China Electrotechnical Society, 2016, 31(24):233-239.

[4] Li, Zhengxi, Zhang, Yongchang, Fan, Shengwen, et al. Predictive Deadbeat Power Control of PWM Rectifier[C]// PCIM Europe 2014; International Exhibition and Conference for Power Electronics, Intelligent Motion, Renewable Energy and Energy Management; Proceedings of. VDE, 2013:1-8.

[5] Jiang W, Ma W, Wang J, et al. Deadbeat Control Based on Current Predictive Correction for Grid-Connected Converter under Unbalanced Grid Voltage[J]. IEEE Transactions on Industrial Electronics, PP(99):1-1.

[6] Iskhakov A, Kobylyansky V, Bekishev A, et al. A direct deadbeat control of a PWM single-phase voltage source inverter[C]// European Conference on Power Electronics and Applications. IEEE, 2013:1-7.

[7] Gholami-Khesht H, Monfared M. Deadbeat direct power control for grid connected inverters using a full-order observer[C]// International Conference on Electric Power and Energy Conversion Systems. IEEE, 2015:1-5.

[8] ZHANG Chao, WANG Zhang-quan, JIANG Yan-jun, HE Xiang-ning. Implementation of a Deadbeat Current Controller for Photovoltaic GridConnected Inverters[J]. Power Electronics, 2007, 41(7):3-5.

[9] Wu T F, Kuo C L, Lin L C, et al. DC-Bus Voltage Regulation for a DC Distribution System With a Single-Phase Bidirectional Inverter[J]. IEEE Journal of Emerging \& Selected Topics in Power Electronics, 2016, 4(1):210-220.

[10] Wu T F, Nien H S, Shen C L, et al. A single-phase inverter system for $\mathrm{PV}$ power injection and active power filtering with nonlinear inductor consideration[J]. IEEE Transactions on Industry Applications, 2005, 41(4):1075-1083. 